\title{
Serum type III procollagen peptide concentration in cryptogenic fibrosing alveolitis and its clinical relevance
}

\author{
JACQUELINE M E KIRK, ERIC D BATEMAN, PATRICIA L HASLAM, \\ GEOFFREY J LAURENT, MARGARET TURNER-WARWICK \\ From the Department of Thoracic Medicine, Cardiothoracic Institute, London
}

\begin{abstract}
The serum concentrations of a metabolite produced during synthesis of type III collagen, type III procollagen peptide (PCP), were measured in patients with cryptogenic fibrosing alveolitis, and the results were related to the course of the disease and its response to treatment. The mean PCP concentration was significantly higher for patients untreated at the time of sampling than for an age and sex matched control group $(p<0.001)$. Seventeen of these patients subsequently started treatment and their response to treatment was assessed by measurement of changes in the transfer coefficient (KCO) and forced vital capacity (FVC) at six months and one year later. Those patients showing a response to treatment, indicated by an increase in the percentage predicted KCO or FVC of more than $10 \%$ one year after starting treatment, had a significantly higher mean PCP concentration ( $p<0.01$ and $p<0.001$ respectively) than patients with stable or deteriorating physiological indices. When the PCP concentrations of these patients were compared with repeat measurements three to six months after the commencement of treatment 14 out of 17 showed a decrease in PCP levels. This percentage change in PCP concentrations correlated significantly with the change in the percentage predicted KCO and FVC at 12 months after the commencement of treatment $(p<0.01)$. These results suggest that measurement of PCP concentrations in patients with cryptogenic fibrosing alveolitis may be useful in the assessment of response to treatment.
\end{abstract}

The clinical management of cryptogenic fibrosing alveolitis presents difficulties because both the prognosis and the response to treatment vary considerably in different patients. ${ }^{1}$ Recent research into this condition has therefore attempted to find markers of disease activity and methods of predicting the response to treatment, so that patients who need treatment can be treated promptly and appropriately.

On the basis of histological studies excess collagen production has been assumed to be an essential feature of cryptogenic fibrosing alveolitis, but this has not been biochemically proved. ${ }^{2}$ Recently, interest in the role of collagen in cryptogenic fibrosing alveolitis has been revived by the finding of several

Address for reprint requests: Dr JME Kirk, Biochemistry Unit, Cardiothoracic Institute, Brompton Hospital, London SW3 6HP.

Accepted 16 May 1984 different types of collagen in the lung. ${ }^{34}$ In particular, it has been suggested that the changes in the relative amounts of the interstitial collagens (types $I$ and III collagens) which occur in cryptogenic fibrosing alveolitis are related to the clinical course of the disease. ${ }^{56}$ Studying open lung biopsy and postmortem lung samples from patients with cryptogenic fibrosing alveolitis using an immunofluorescent technique, Bateman and colleagues ${ }^{5}$ suggested $\sigma$ increased type III collagen in patients with "active" N disease.

While these studies may be of value clinically, the 0 study of lung biopsy samples has certain disadvantages. Firstly, they may be affected by sampling var- $\frac{\mathscr{D}}{\mathscr{D}}$ iation. ${ }^{7}$ Secondly, open lung biopsies are only $\stackrel{\infty}{\rightarrow}$ rarely repeated, so that these techniques cannot be 0 used to monitor the course of an individual patient's disease. Finally, not all patients are able to undergo open lung biopsy. A technique has been developed $\mathbb{D}$ recently which can detect a byproduct of type III 
collagen synthesis in the blood. ${ }^{10}$ Type III collagen is synthesised initially in a precursor form as type III procollagen, which has extension peptides at the $N$ and $C$-terminal ends of the molecule. The findings have been reviewed by Fessler and Fessler. ${ }^{11}$ These peptides are removed by specific peptidases and the $N$-terminal peptide can be detected, by means of a sensitive radioimmune assay technique, in normal serum. ${ }^{11}$ Rohde and colleagues used this technique and found increased concentrations of procollagen peptides in the serum of patients with various liver diseases and with rheumatoid arthritis. ${ }^{12}$

This study explores changes in serum type III procollagen peptide concentration in patients with cryptogenic fibrosing alveolitis and assesses their value in management.

\section{Methods}

Seventy one patients with cryptogenic fibrosing alveolitis were studied, of whom 11 were excluded from subsequent analysis because of overt rheumatoid arthritis or abnormal results in liver function tests, both of which are known to be associated with raised serum procollagen peptide concentrations. ${ }^{12}$ The remaining 60 patients were compared with 45 normal subjects. All patients fulfilled the diagnostic criteria described by Turner-Warwick and colleagues. ${ }^{13}$ Serum procollagen peptide concentration was measured in 10 patients with nonfibrosing lung disorders. Twenty three patients with cryptogenic fibrosing alveolitis were not having treatment at the time of sampling, and the results from these patients were compared with those from a group of 21 age and sex matched control subjects. Treatment with either high dose steroids or steroids with cyclophosphamide was started subsequently in 17 of these patients; procollagen peptide concentrations were measured before treatment and again three to six months later. In 10 patients repeat procollagen peptide measurements were made on several more occasions, up to 18 months after starting treatment. Normal control samples were taken from members of staff of the Brompton Hospital, the Cardiothoracic Institute, and the Chester Beatty Research Institute. The 10 patients with nonfibrosing lung disorders were inpatients at the Brompton Hospital who had been admitted because of an acute exacerbation of chronic obstructive lung disease (5), asthma (2), or bronchiectasis (3).

The ratio of type III to total type I + III collagen was measured biochemically (as described later) in five postmortem samples and seven open lung biopsy samples, and these results were compared with the serum procollagen peptide concentration measured just before death or biopsy.

\section{CLINICAL ANALYSIS}

The clinical course of the patients' disease was assessed at intervals of six months and one year after the start of treatment on the basis of the following criteria: (1) physiological measurements of the forced vital capacity (FVC) and the transfer coefficient (KCO), both expressed as percentages of the value predicted for the patient's age, sex, and height $^{14}$; (2) assessment of chest radiographic appearances (on the basis of the ILO U/C classification for the pneumoconiose ${ }^{15}$ ) with an independent assessor.

\section{HISTOLOGICAL ASSESSMENT}

The histological assessment was performed on 11 lung samples by an independent observer without reference to other data on the patients. The samples were fixed in formalin, embedded in paraffin wax, sectioned, and stained with haematoxylin and eosin or elastic and van Gieson stains. A four point score, scale $1-4$ ( $1=$ normal, $2=$ mild, $3=$ moderate, $4=$ severe), was used to assess the numbers of inflammatory cells in alveoli and interstitium and the severity of interstitial fibrosis and architectural destruction. This grading procedure was similiar to that used in previous studies. ${ }^{6816-19}$

\section{SERUM COLLECTION}

Blood was taken from fasting patients, clotted for two hours at $37^{\circ} \mathrm{C}$, and then centrifuged. The serum was separated and aliquots were stored at $-20^{\circ} \mathrm{C}$ until they were used.

\section{PROCOLLAGEN PEPTIDE MEASUREMENTS}

The procollagen peptide measurements were made with radioimmune assay "kits", which were kindly provided by Dr Bremer of Hoechst Pharmaceuticals. The method was that of Rohde and colleagues. ${ }^{12}$ The serum samples (diluted to $1: 4,1: 16$, and 1:64 with phosphate buffered saline) were incubated at $4^{\circ} \mathrm{C}$ overnight with prepared antiserum (raised in rabbits) to bovine type III procollagen. Excess procollagen peptide labelled with iodine 125 was added and the incubation continued for a further seven hours. Finally, the immune complexes were precipitated, with an excess of goat antiserum to rabbit IgG, and separated by centrifugation, and the amount of radioactivity in the precipitate was measured with a Packard autogamma scintillation spectrophotometer (S266). A standard curve (dilutions of a known amount of unlabelled procollagen peptide being used) was prepared by a similar method. The amount of procollagen which gave $50 \%$ inhibition of binding of labelled antigen was noted and used to calculate the concentration of procollagen peptide in the samples. For the con- 
struction of the standard curve all the measurements were carried out in triplicate where errors were less than 5\%. Two constant serum samples were included in each kit to assess variation between kits. The variation between different kits was less than $25 \%$ and the variation within the same kit was less than $5 \%$.

BIOCHEMICAL MEASUREMENTS OF TYPES I AND III COLLAGENS IN LUNG BIOPSY AND NECROPSY SAMPLES

In 12 cases the percentage of type III collagen, in the total of type I and type III collagen, was measured biochemically in open lung biopsy $(8)$ or postmortem samples (4). The method used was developed in our laboratory ${ }^{20}$ and modified for use on human lung samples. ${ }^{6}$ It required the extraction of collagen by sodium dodecyl sulphate and its division into smaller peptides by cyanogen bromide. These were then separated by polyacrylamide gel electrophoresis and stained with Coomassie Blue. Finally, quantification was performed by densitometric scanning. The results were compared with the procollagen peptide concentrations taken just before biopsy or necropsy.

\section{SERUM FACTORS}

To exclude patients with incidental liver disease from this study the serum aspartate transaminase (AST) activity was measured in all patients at the same time as the procollagen peptide sample. Serum AST activity was chosen as it had previously been found to show significant correlation with serum procollagen peptide concentration. ${ }^{12}$

The erythrocyte sedimentation rate (ESR), serum albumin, and total serum protein were measured. Serum urea and creatinine were measured in all patients to exclude rises in procollagen peptide concentrations due to impaired renal clearance. Immunological investigations included measurements of antinuclear antibodies by a double layer immunofluorescent technique and measurements of rheumatoid factor, latex agglutination, and differential agglutination with the standard test with sensitised sheep red cells.

\section{STATISTICAL ANALYSIS}

Correlations between procollagen peptide concentrations and biopsy and clinical data were examined by means of the product-moment coefficient, significance being tested in the usual way. Differences between means were assessed with Student's $t$ test and the Mann-Whitney U test.

\section{Results}

COMPARISON BETWEEN PATIENTS, NORMAL SUBJECTS, AND PATIENTS WITH NON-FIBROSING LUNG DISORDERS

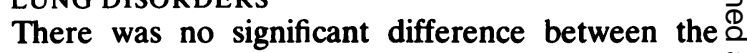
mean serum procollagen peptide concentration in $\%$ normal subjects $(8.8(\mathrm{SD} 2 \cdot 3) \mathrm{ng} / \mathrm{ml})$ and that in $\vec{\circ}$ patients with non-fibrosing lung disorders $(9.6(3.0)$ $\mathrm{ng} / \mathrm{ml}$ ). The mean procollagen peptide concentra- $\bar{\omega}$ tion in the 60 patients with cryptogenic fibrosing alveolitis, however $(10.4 \quad(4 \cdot 2) \mathrm{ng} / \mathrm{ml})$, was $\vec{x}$ significantly greater than the mean of the control $\omega_{0}$ samples $(p<0.01)$. Only one of the 10 patients in the non-fibrosing lung disorder group had a raised procollagen peptide concentration (that is, greater N than the mean of the normal group +2 SD), com- 0 pared with 16 of the $60(27 \%)$ patients with cryptogenic fibrosing alveolitis. Individual values for $O$ serum procollagen peptide concentration in the $23 \%$ patients with cryptogenic fibrosing alveolitis untrea- $\frac{0}{8}$ ted at the time of sampling are shown in figure 1. Of $^{\stackrel{\complement}{-}}$ these, 10 (that is, $44 \%$ ) had procollagen peptide $\vec{\varphi}$ concentrations (mean +2 SD) above control values. $\rightarrow$ The mean procollagen peptide concentration of this group (12.6 (2.9) $\mathrm{ng} / \mathrm{ml})$ was significantly higher? than that of the age and sex matched control group $(8.8(2.3) \mathrm{ng} / \mathrm{ml})(\mathrm{p}<0.001)$.

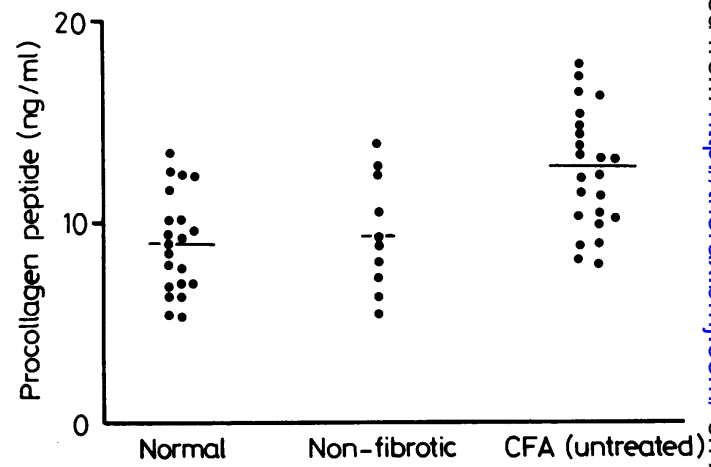

Fig 1 Serum type III procollagen peptide concentration in 23 patients with untreated cryptogenic fibrosing alveolitis (CFA), an age and sex matched group of 21 normal subjects, and 10 patients with non-fibrosing lung disorders. $N$ Mean values are indicated by horizontal bars.

RELATIONSHIP BETWEEN PROCOLLAGEN PEPTIDE CONCENTRATION AND OTHER SERUM FACTORS

There was no correlation between serum procol- 0 lagen peptide concentration and serum total protein $\overline{\underline{Q}}$ albumin, or globulin concentrations. Similarly, there was no correlation with ESR or immunoglobulifi concentrations. 
There was no significant difference in serum procollagen peptide concentration between patients positive for rheumatoid factor, in the absence of overt arthritis, and those negative for rheumatoid factor.

COMPARISON BETWEEN SERUM TYPE III PROCOLLAGEN PEPTIDE CONCENTRATION AND THE RATIO OF TYPE III TO TYPE I COLLAGEN MEASURED BIOCHEMICALLY IN LUNG TISSUE SAMPLES

Figure 2 shows that there was a positive correlation between the percentage of type III of the total type I + III collagen in lung biopsy and postmortem sam-

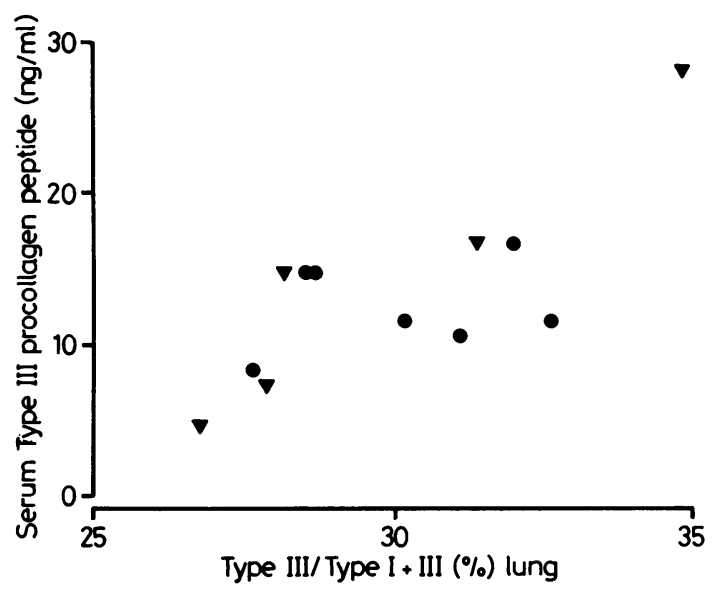

Fig 2 Relationship between serum type III procollagen peptide concentration and type III collagen as percentage of the total type I + type III collagen in lung tissue. -biopsy samples; - -necropsy samples.

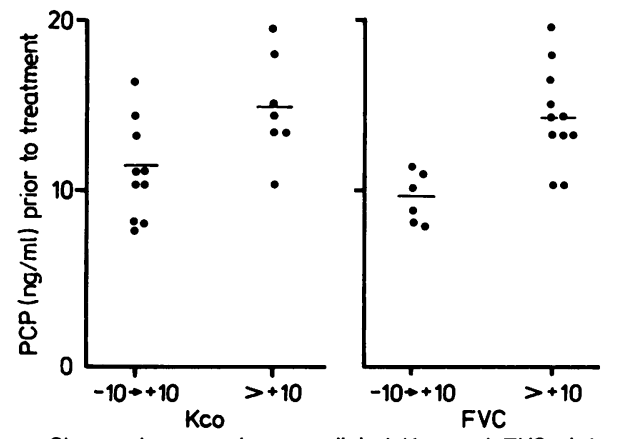

Change in percentage predicted Kco and FVC at 1 year

Fig 3 Serum type III procollagen peptide (PCP) concentration measured before treatment in patients showing improvement of more or less than $10 \%$ of the predicted normal value of either transfer coefficient (KCO) or forced vital capacity (FVC) one year after the start of treatment. ples and the serum procollagen peptide concentration measured at this time $(\mathrm{r}=0.7, \mathrm{p}<0.01)$.

\section{RELATIONSHIP BETWEEN PROCOLLAGEN} PEPTIDE LEVELS AND CLINICAL INDICES

There was no relationship between procollagen peptide concentration and the duration of symptoms either in the patients with untreated cryptogenic fibrosing alveolitis or in the whole group of patients with cryptogenic fibrosing alveolitis. Similarly, there was no relationship between procollagen peptide concentration and the clinical degree of dyspnoea or the physiological measurements made at the time of sampling.

\section{RELATIONSHIP BETWEEN SERUM PROCOLLAGEN PEPTIDE CONCENTRATION AND DEGREE OF FIBROSIS \\ There was no correlation between the serum procol- lagen peptide concentrations measured before biopsy or death and the degree of fibrosis as assessed histologically or the degree of cellularity, whether intra-alveolar or interstitial.}

\section{RELATIONSHIP BETWEEN SERUM PROCOLLAGEN PEPTIDE CONCENTRATION AND RESPONSE TO TREATMENT}

Figure 3 shows the relationship between serum procollagen peptide concentrations before treatment and the subsequent changes in lung function one year later. The data show that the seven patients who showed an improvement in the percentage predicted $\mathrm{KCO}$ of greater than $10 \%$ one year after the

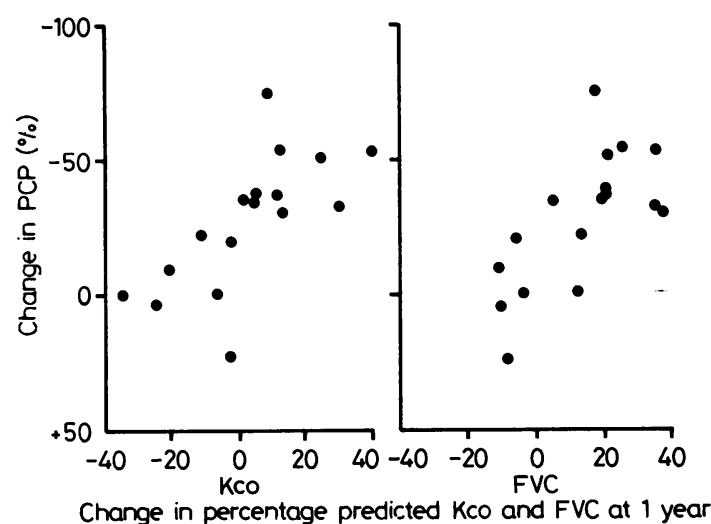

Fig 4 The response to treatment at 12 months. The percentage change in serum type III procollagen peptide (PCP) concentration between values before the start of treatment and 3-6 months later, and change in the percentage predicted transfer coefficient $(\mathrm{KCO})$ and forced vital capacity (FVC) between values before the start of treatment and values one year later. 
commencement of treatment had a significantly higher mean procollagen peptide $(15.0(3.1) \mathrm{ng} / \mathrm{ml})$ than the 10 patients who did not show such improvement $(11.4(2.8) \mathrm{ng} / \mathrm{ml})(\mathrm{p}<0.01)$. Similarly, 11 patients with an increase in percentage predicted FVC of greater than $10 \%$ one year after commencement of treatment had a significantly higher mean procollagen peptide $(14.5(2 \cdot 9) \mathrm{ng} / \mathrm{ml})$ than six patients with a lesser improvement or deterioration $(9.8(1.5) \mathrm{ng} / \mathrm{ml})(\mathrm{p}<0.001)$.

After treatment with corticosteroids or cyclophosphamide or both, 14 out of 17 patients showed a decreased serum procollagen peptide concentration three to six months later. This percentage change in procollagen peptide at three to six months correlated significantly with the change in the percentage predicted $\mathrm{KCO}$ found at 12 months ( $\mathrm{r}=$ $0.66 \mathrm{p}<0.01)$ and with the change in the percentage predicted FVC at 12 months $(r=0.66 p<$ 0.01) (fig 4).

\section{Discussion}

Although there are several possible explanations for increased serum procollagen peptide concentration in patients with cryptogenic fibrosing alveolitis, there are three reasons for believing that the. concentrations in this study do reflect type III collagen metabolism in the lung. Firstly, a correlation was found between serum procollagen peptide concentration and the ratio of type III to type I collagen in lung tissue measured biochemically. Secondly, studies by Low and colleagues ${ }^{21}$ have shown greater increases in type III procollagen peptide concentration in bronchopulmonary lavage fluid than serum in patients with cryptogenic fibrosing alveolitis. Finally, in the present study patients were excluded who had other conditions in which type III procollagen peptide concentrations are known to be raised $^{12}$-for example, rheumatoid arthritis, liver disease, and impaired renal clearance.

In view of the way in which type III procollagen peptides are produced, the raised concentrations found in cryptogenic fibrosing alveolitis are presumably the result of increased type III collagen synthesis (for review see reference 11). In animal models of pulmonary fibrosis in vitro ${ }^{22} 23$ and in vivo ${ }^{24}$ there is evidence for increased total collagen synthesis rates, although as yet there is no evidence of this in man. Fulmer and colleagues failed to demonstrate increased collagen synthesis in minced lung tissue from patients with cryptogenic fibrosing alveolitis, ${ }^{2}$ but the method used has been questioned. ${ }^{25}$ In animal models of pulmonary fibrosis, despite the increase in overall collagen synthesis rates, there is no evidence that the amount of type III collagen is increased more than that of type I collagen. ${ }^{22} 2627$ There is, however, some in vitro evidence of increased type I collagen synthesis. ${ }^{28}$

Interestingly, serum procollagen peptide concentration, which presumably reflects type III collagen synthesis, is correlated with the proportion of type III collagen found in lung tissue. This implies that the proportion of type III collagen present in the lung tissue is related to changes in synthesis rates, although the possibility of changes in the rates of degradation cannot be excluded. The latter are believed to be important in pulmonary fibrosis in animal models. ${ }^{24}$ Furthermore, as the ratio of type III to type I collagen in lung tissue was measured in the present study, rather than the absolute amounts of type III collagen, the correlation with type III procollagen peptide concentrations implies that changes in the proportion of type III collagen in the lung do not depend entirely on changes in the amounts of type I collagen. Finally, the correlation with the proportion of type III collagen in the lung samples suggests that increases in the rate of type III collagen synthesis persist until changes in the amounts of type III in the lung occur. As previous evidence suggests that a greater proportion of type I than of type III collagen occurs in late disease, ${ }^{6}$ our results imply that increases in the rate of type III collagen synthesis occur before increases in the rate of type I collagen synthesis. Type I procollagen peptide concentrations were not measured in the present study, but as type I procollagen peptides are known to be cleaved more rapidly than type III peptides, they could possibly be a more sensitive indicator of overall collagen synthesis than type III procollagen peptide concentrations.

Serum procollagen peptide measurements are easily and quickly made with the radioimmunoassay kit (now commercially available), and serial measurements may be carried out during the course of the disease with minimal discomfort to the patient. The technique therefore has the considerable advantage of simplicity and non-invasiveness over other methods of assessing disease activity, such as bronchopulmonary lavage ${ }^{17}$ and lung biopsy. ${ }^{816}$

Several factors may confuse the interpretation of procollagen peptide concentrations in patients with cryptogenic fibrosing alveolitis. The first problem is the lack of specificity for lung type III collagen previously mentioned, so that measurements of serum procollagen peptide concentration are appropriate only in patients with cryptogenic fibrosing alveolitis alone. In our study 17 of 71 patients were excluded because they had other associated conditions. Furthermore, the procollagen peptide concentrations found in cryptogenic fibrosing alveolitis are not as high as those found in some other conditions. 
Thus in liver disease from two to 20 times the normal serum concentrations were found. ${ }^{12}$ Finally, although there is a significant difference between the mean procollagen peptide concentration in untreated patients with cryptogenic fibrosing alveolitis and normal subjects, about $50 \%$ of patients have levels within the normal range. For all these reasons the test does not necessarily help diagnosis. Furthermore, there have so far been no reports of studies of procollagen peptide concentrations in acute, less obviously fibrotic lung disorders-for example pneumonia. These studies are being undertaken at present.

The study by Bateman and colleagues ${ }^{5}$ that suggested increased type III collagen in active disease led us to believe that serum type III procollagen peptide concentrations could be useful markers of disease activity in cryptogenic fibrosing alveolitis. In the present study the difference between the mean procollagen peptide concentration of patients showing a significant response to treatment and that of those who failed to respond suggests that a raised procollagen peptide concentration is related to a better response to treatment. The overlap between the two groups, however, makes interpretation of single estimations of procollagen peptide difficult in individual patients. The serial measurements of procollagen peptide, taken before the commencement of treatment and then three to six months later, are of greater value in the assessment of response to treatment. Serial measurements of procollagen peptide also have the advantage of increased accuracy since all samples may be stored until they can be measured with the same kit. Rohde and colleagues showed that storage of samples at $-20^{\circ} \mathrm{C}$ for up to one year had no effect on procollagen peptide measurements, ${ }^{12}$ and in this way possible errors due to differences between one kit and another are eliminated. The decrease in procollagen peptide associated with a good response to treatment suggests that interference with type III collagen synthesis, either directly or indirectly, is an important feature in the treatment of cryptogenic fibrosing alveolitis. There is evidence, reviewed by Cutroneo and colleagues, ${ }^{29}$ that steroids selectively decrease rates of collagen synthesis both in cell culture and in animal studies in vivo. It seems unlikely that the reduction in procollagen peptide produced by steroids and cyclophosphamide is non-specific, as patients with stable disease showed either no decrease or an increase in serum procollagen peptide concentration. To confirm this, studies are being undertaken to measure the effect of steroids on procollagen peptide levels in non-fibrosing lung conditions such as asthma. Preliminary results on one asthmatic patient showed no change in procollagen peptide concentration three weeks after she had started prednisolone.

In this study only type III procollagen peptide concentrations were measured; since it is probable, however, that in late cryptogenic fibrosing alveolitis the ratio of type I to type III collagen is increased, ${ }^{3630}$ measurement of type I procollagen peptide might prove useful as an additional method of "staging" the disease. In a study of patients with Paget's disease by Taubman and colleagues ${ }^{31}$ the $C$-terminal peptide of type I procollagen peptide has been measured in serum in patients before and after treatment with disodium etidronate. The results were similar to those of the present study, showing abnormally high concentrations of type I procollagen peptide in the patients' serum which were reduced after treatment.

In our study of 11 cases there was no relationship between the degree of fibrosis assessed histologically and serum procollagen peptide concentration. This was possibly because the bulk of the collagen is type $\mathrm{I}^{36}$ and therefore a combination of type III and type I procollagen peptide concentrations would give a better estimation. A further reason may be that, as has been shown in animal models, ${ }^{7}$ changes in collagen metabolism occur before fibrosis becomes visible histologically. The study by Rohde and colleagues in liver disease did succeed in demonstrating a relationship between procollagen peptide concentrations and portal inflammation, periportal necrosis, and intralobular necrosis, but no relationship was found between portal and intralobular fibrosis and procollagen peptide levels. ${ }^{12}$

Changes in procollagen peptide concentrations after commencement of treatment may be useful in the assessment of the response to treatment in patients with cryptogenic fibrosing alveolitis. Furthermore, serial procollagen peptide measurements may also prove to be useful in assessing patients during treatment, but detailed prospective studies need to be performed before their value in this respect can be assessed.

Procollagen peptide immunoassay kits were kindly provided by Dr Bremer, Hoechst Pharmaceuticals, Frankfurt, Germany. We are grateful to Professor B Heard for performing the histological assessment. Support for JMEK and much of this study came from a grant from Action Research for the Crippled Child. The work was also supported by the Medical Research Council.

\section{References}

' Turner-Warwick M, Burrows B, Johnson A. Cryptogenic fibrosing alveolitis: clinical features and their influence on survival. Thorax 1980;35:171-80. 
${ }^{2}$ Fulmer JD, Bienkowski RS, Cowan MJ, et al. Collagen concentration and rates of synthesis in idiopathic pulmonary fibrosis. Am Rev Respir Dis 1980;122:289301.

${ }^{3}$ Madri JA, Furthmayr H. Collagen polymorphism in the lung. An immunohistochemical study of pulmonary fibrosis. Hum Pathol 1980;11:355-65.

${ }^{4}$ Laurent GJ. Collagen in normal lung and during pulmonary fibrosis. In: Cumming G, Bonsignore G, eds. Cellular biology of the lung. New York: Plenum Press, 1982:311-20.

${ }^{5}$ Bateman ED, Turner-Warwick M, Haslam $P$, Adelmann-Grill BC. Cryptogenic fibrosing alveolitis: prediction of fibrogenic activity from immunohistochemical studies of collagen types in lung biopsy specimens. Thorax 1983;38:93-101.

${ }^{6}$ Kirk JME, Heard BE, Kerr I, Turner-Warwick M, Laurent GJ. Quantitation of types I and III collagen in biopsy lung samples from patients with cryptogenic fibrosing alveolitis. Collagen Rel Res 1984;4:169-82.

${ }^{7}$ Laurent GJ, McAnulty RJ, Corrin B, Cockerill P. Biochemical and histological changes in pulmonary fibrosis induced in rabbits with intratracheal bleomycin. Eur J Clin Invest 1981;11:441-8.

${ }^{8}$ Winterbauer RH, Hammar SP, Hallman KO. Diffuse interstitial pneumonitis: clinicopathologic correlations in 20 patients treated with prednisolone/azathioprine. Am J Med 1978;65:661-72.

${ }^{9}$ Nowack H, Olsen BR, Timpl R. Characterization of the aminoterminal segment in type III procollagen. Eur $J$ Biochem 1976; 70:205-16.

${ }^{10}$ Rohde H, Hahn E, Timpl R. Radioimmunoassay for aminoterminal procollagen peptides in liver disease. Fresenius Zeitschrift für'Analytische Chemie 1978; 290: 151-2.

"Fessler JH, Fessler LI. Biosynthesis of procollagen. Annu Rev Biochem 1978;47:129-62.

${ }^{12}$ Rohde H, Vargas L, Hahn E, Kalbfleisch H, Bruguera M, Timpl R. Radioimmunoassay for type III procollagen peptide and its application to human liver disease. Eur J Clin Invest 1979;9:451-9.

${ }^{13}$ Turner-Warwick M, Haslam P. Antibodies in some chronic fibrosing lung diseases. (1) Non organ-specific autoantibodies. Clin Allergy 1971;1:83-95.

${ }^{14}$ Cotes JE. Lung function: assessment and application in medicine. 4th ed. Oxford: Blackwell Scientific Publications, 1979.

is International Labour Office and Unio Contra Cancerem (ILO U/C). International classification of radiographs of pneumoconioses. Geneva: ILO, 1971. (Occupational Safety and Health Series No 22.)

${ }^{16}$ Wright PN, Heard BE, Steel SJ, Turner-Warwick M. Cryptogenic fibrosing alveolitis: assessment by graded trephine lung biopsy histology compared with clinical, radiographic and physiological features. $\mathrm{Br} J \mathrm{Dis}$ Chest 1981;75:61-70.

17 Haslam PL, Turton CWG, Heard B, et al. Bronchoalveolar lavage in pulmonary fibrosis: comparison of cells obtained with lung biopsy and clinical features. Thorax 1980;35:9-18.

${ }^{18}$ Stack BHR, Choo-Kang FJ, Heard BE. The prognosis of cryptogenic fibrosing alveolitis. Thorax 1972; 27:535-42.

${ }^{19}$ Crystal RG, Fulmer JD, Roberts WC, Moss ML, Line BR, Reynolds MR. Idiopathic pulmonary fibrosis. Clinical, histologic, radiographic, physiologic, scintigraphic, cytologic and biochemical aspects. Ann Intern Med 1976;85:769-88.

${ }^{20}$ Laurent GJ, Cockerill P, McAnulty RJ, Hastings JB. A simplified method for quantitation of the relative amounts of type I and type III collagen in small tissue samples. Anal Biochem 1981;113:301-12.

${ }^{21}$ Low RB, Cutroneo KR, Davis GS, Giancola MS. Lavage type III procollagen $N$-terminal peptides in human pulmonary fibrosis and sarcoidosis. Lab Invest 1983;48:755-63.

22 Reiser KM, Last JA. Pulmonary fibrosis in experimental acute respiratory disease. Am Rev Respir Dis 1981;123:58-63.

${ }^{23}$ Clarke JG, Overton JE, Marino BA, Uitto J, Starcher BC. Collagen biosynthesis in bleomycin-induced pulmonary fibrosis in hamsters. J Lab Clin Med 1980;96:943-53.

${ }^{24}$ Laurent GJ, McAnulty RJ. Protein metabolism during bleomycin-induced pulmonary fibrosis in rabbits. In vivo evidence for collagen accumulation due to increased synthesis and decreased degradation of the newly synthesised collagen. Am Rev Respir Dis 1983;128:82-88.

${ }^{25}$ Laurent GJ. Rates of collagen synthesis in lung, skin and muscle obtained in vivo by a simplified method using [3H] proline. Biochem J 1982;206:535-44.

${ }^{26}$ Kirk J, Heard BE, Kerr I, Cockerill P, Laurent GJ. Quantitation of types I and III collagen in pulmonary fibrosis. Eur J Clin Invest 1983;13 (2 part 2): A21 (abstract).

${ }^{27}$ Reiser KM, Hesterberg TW, Haschek WM, Last JA. Experimental silicosis. (1) Acute effects of intratracheally instilled quartz on collagen metabolism and morphologic characteristics of rat lungs. Am J Pathol 1982;107:176-85.

${ }^{28}$ Haschek WM, Klein-Szanto AJ, Last JA, Reiser KM, Witschi M. Long term morphologic and biochemical features of experimentally-induced lung fibrosis in the mouse. Lab Invest 1982;46:438-9.

${ }^{29}$ Cutroneo KR, Rokowski R, Counts DF. Glucocorticoids and collagen synthesis: comparison of in vivo and cell culture studies. Collagen Rel Res 1981;1:557-68.

${ }^{30}$ Seyer JM, Hutcheson ET, Kang AH. Collagen polymorphism in idiopathic chronic pulmonary fibrosis. J Clin Invest 1976;57:1498-507.

31 Taubman M, Kammerman S, Goldberg B. Radioimmunoassay of procollagen in serum of patients with Paget's disease of bone. Proc Soc Exp Biol Med 1976; 152:284-7. 